\title{
Assessment of Heavy Metal (Ni, Cr) Contamination and Spatial Distribution in Surface Sediment and Soil in the Area of Lake Sawa
}

\author{
Ayad Kadhim Ali ${ }^{1}$, Ali Khalil Alkhafajy ${ }^{2}$ \\ ${ }^{1}$ Assistant Professor, Department of Soil and Water in Agriculture College, University of Kufa,Iraq. \\ ${ }^{2}$ Department of Soil and Water in Agriculture College, University of Almuthanna, Iraq
}

\begin{abstract}
It is widely accepted that heavy metal contamination in sediment and soil is one of the largest threats to environmental and human health. Sediments are the principle sinks for heavy metals in aquatic environments, and can result in a secondary contamination source affecting the ecosystem. Analysis of heavy metal amounts in sediments and comparison with reference levels is a reliable indicator of ecosystem health. However, understanding the distribution of pollutants is among most essential information for environmental research and critical for environmental management and decision-making.28 samples were collected from surface (0-15 cm) layers of sediments in the area of Lake Sawa. The level of pollution attributed to heavy metals was evaluated using $X$-Ray fluorescence analysis and comparison with reference levels of world health organization 2003(maximum allowable concentrations in soil),Spatial distribution patterns of metals in sediments were demonstrated by employing ordinary kriging interpolation. The Results of heavy metal pollution analysis reveal a significant anthropogenic impact on the area of Lake Sawa with concentrations of several heavy metals in surface layer of sediments exceeding maximum concentrations allowable by WHO. Detected levels of chromium (Cr), nickel (Ni), demonstrate a significant pollution anomaly and high potential threat to the water ecosystem and even human health by exceeding maximum allowable concentration. A comparison of heavy metal amounts and spatial distribution patterns in the layer of sediments reveals much higher pollution levels in the surface $(0-15 \mathrm{~cm})$. Spatial distribution analysis demonstrates irregular distribution of most metals due to complexity of influencing physical and chemical processes, but the general trend of high concentration.
\end{abstract}

Keywords: Heavy metal, Kriging, Spatial distribution, Pollution, Lake

\section{Introduction}

Decomposition of rock and organic matter for many years has resulted in soil formation. Soils as mentioned are critical environments where rock, air and water interface [1]. Naturally in soils, chemical elements occur as components of minerals though at certain concentrations some may be toxic. The chemical elements such as metals cannot break down, but their characteristics may change so that they can be easily taken up by plants or animals [1]. Soil can be said to be clean where the substance under environmental concern occur in concentrations equal to or lower than the value found in nature, which is used as reference and normally called background concentration. The background concentration is the total element concentration obtained from soils that had not been affected by human activity. However, certain actions such as past land use; current activities on the site, and nearness to pollution sources have all affected soil properties [2].Contamination refers to the condition of land or water where any chemical substance or waste has been added at above background level and represents, or potentially represents, an adverse health or environmental impact. It can result in a potential financial, social and environmental cost [3].

\section{Heavy Metals}

Several meanings have been assigned to heavy metals. Heavy metals can also be loosely defined as a subset of elements that exhibit metallic properties. It comprises the transition metals, some metalloids, lanthanides, and actinides. Using density as a defining factor, [4] also defined heavy metals as those having a specific density of more than $5 \mathrm{~g} / \mathrm{cm} 3$ [5]. They can also be chemical elements with the density greater than $4 \mathrm{~g} / \mathrm{cm} 3$ found in all kinds of soils, rocks and water in terrestrial and freshwater ecosystem [6]. Heavy metals can be said to be referred to as any metallic element that has a relatively high density and is toxic or poisonous even at low concentration [7]. Heavy metals have the ability to enter the human body through inhalation, ingestion and dermal contact absorption [6]. Heavy metals contamination threatens agriculture and other food sources for human population as well as poor vegetation growth and lower plant resistance against forests pests. Thereby having impact on the quality of food, groundwater, microorganisms and plant growth [8].The toxicity of heavy metals is one of the major current environmental health concerns and potentially dangerous because of bio-accumulation through the food chain [6].

\section{Chromium (Cr)}

Chromium (Cr) is a cubic crystal, steel gray, very hard and a d-block metal. It is a transition metal which belongs to period 4 and group 6 . On the periodic table chromium (Cr) has atomic number 24, atomic mass 52, density $7.19 \mathrm{~g} / \mathrm{cm} 3$, melting point $2130 \mathrm{~K}$ and boiling point $2755 \mathrm{~K}$. Chromium $(\mathrm{Cr})$ as a primary ore product is mined in the form of mineral chromite, FeCr2O4 [9]. Chromium (Cr) is required for carbohydrate and lipid metabolism, utilization of amino acids and as pigments for paints, cement, paper, rubber, metal plating for prevention of corrosion, leather tanning and textile colour pigments [10]. Exposure to chromium (Cr) can lead to allergic dermatitis in humans, bleeding of 


\section{International Journal of Science and Research (IJSR) \\ ISSN (Online): 2319-7064}

Index Copernicus Value (2013): 6.14 | Impact Factor (2015): 6.391

the gastrointestinal tract, cancer of the respiratory tract and ulcers of the skin. Then also damage to the mucus membrane, liver and kidney damage [6].

\section{Nickel (Ni)}

Nickel (Ni) is also cubic crystal, silvery and a d-block metal. This is a transition metal belonging to period 4 and group 10. It has atomic number 28, atomic mass 58.7, density $8.9 \mathrm{~g} / \mathrm{cm} 3$, melting point $1726 \mathrm{~K}$ and boiling point of $3005 \mathrm{~K}$. It is an element that occurs in the environment only at very low levels and is essential in small doses, but it can be dangerous when the maximum tolerable amounts are exceeded [11]. It is used in the manufacture of stainless steel, coins, nickel for armor plates, burglarproof vaults, vegetable oils, ceramics and Ni-Cd batteries [10]. Nickel (Ni) can result in lung, liver and kidney damage. In high quantities, Ni can also cause cancer, respiratory failure, birth defects, allergies, dermatitis, eczema, nervous system and heart failure [12].Cu, $\mathrm{Zn}$ and $\mathrm{Ni}$ are essential trace metals in the human body, but if the body takes excessive $\mathrm{Cu}, \mathrm{Zn}$ and Nifrom the outside environment, they will damage human health. $\mathrm{Ni}$ and $\mathrm{Cu}$ are tumor promoting factors, whose carcinogenesis effect has attracted global concerns. Workers who are in close contact with the nickel powder are more likely to suffer from respiratory cancer, and the content of $\mathrm{Ni}$ in the environment is positively correlated with nasopharyngeal carcinoma [13].

\section{Study Area}

Sawa Lake, $23 \mathrm{~km}$ west of the city of Samawah, in the southwestern part of the AL-Muthana province. between the latitudes (31 17 43.10) (31 19 49.79) and longitudes ( 4501 46.61) (44 5929.01 ) and equivalent to the (Path) 168 and (Row) 38 as satellite coordinates can be accessed by road, which runs parallel to the river which is known ALA'tshaan as a branch of the Euphrates River.

Lake with an elongated shape, toward the north-west and the south-east, while the study area as a flat land and are considered as part of the southern part of Western Sahara. the lake rises $18 \mathrm{~m}$ above sea level while Rising from ground level neighbors about 2 - $5 \mathrm{~m}$ which prevents seen only from close distances, Topographic gradient for this region generally increases from north-east to south-west with average about 2.7 meters per kilo meters. There is no source of surface water and feeds the lake water and it is possible that groundwater is the source that Fed. The area of the lake is about more than $5.5 \mathrm{~km} 2$ length of about $4.75 \mathrm{~km}$ long and at the widest point is about $1.75 \mathrm{~km}$. either depth it is the first two radio bands which is parallel to the outside of its barrier with ranging between 2.5 to $4 \mathrm{~m}$ and $5-5.5 \mathrm{~m}$ which covers more than $70 \%$ of the area of the lake.The study area characterized by many important phenomena of sabkha and dunes devoid of Lake Sedimentation processes mechanical except micro dust particles from the atmosphere [14].

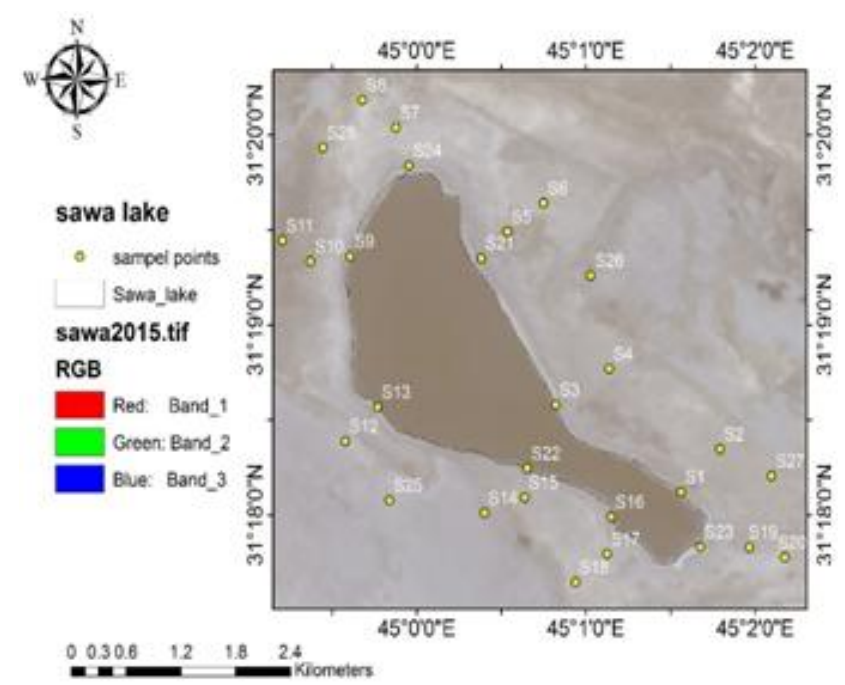

Figure 1: Map of the study area and the surrounding areas with sample points

\section{Methodology}

\section{Soil Sampling and Chemical Analysis}

Soil samples were collected at $0-15 \mathrm{~cm}$ depths from each of the 28 sampling locations across the study area.Soil samples were collected on March 15 of 2015; global positioning system (GPS) receiver (Garmin GPS map 60 CSX).The collected soil samples were dried and passed through a 2 mm sieve, Soil samples (approximately $3 \mathrm{~g}$ ) were analyzed by $X$-ray fluorescence (XRF) technique to evaluate the soil pollution with heavy metals ( $\mathrm{Cr}$ and $\mathrm{Ni}$ ) concentration.

Gis arcmap 10.0 program used to create database map for area of the lake to produce spatial distribution maps of each element by linking quantitative data with spatial data and it represented by sampling sites. By using kriging tool in arcmap gis two maps are created for $\mathrm{Cr}$ and $\mathrm{Ni}$ in the area.

\section{Spatial Interpolation Methodology}

The kriging interpolation technique was used to demonstrate spatial distribution patterns of heavy metals in the surface sediments in the area of Lake sawa,Kriging is a method of interpolation, which predicts unknown values from data observed at known locations. This method uses a variogram to express spatial variation, and minimizes the error of predicted values which are estimated by spatial distribution [15].In a geostatistics context, kriging can be defined as a generalized linear regression technique used with a variogram model for spatial data interpolation.In this study, the spatial data are the measured concentrations of metals in sediment.

\section{Results and Discussion}

\section{Soil Chemical Concentration}

The chemical concentration of the soils at 0-15 cm depths of the surface soils in (mg. $\mathrm{kg}^{-1}$ ) in study area are shown in Table 1.

the results indicated that Chromium was reported to be rich and very rich in the soils of arid and semi arid regions; up to 2400 ppm Cr was reported in soils of such regions [16]. A grand average for world soil was reported as 200 ppm 


\section{International Journal of Science and Research (IJSR) \\ ISSN (Online): 2319-7064 \\ Index Copernicus Value (2013): 6.14 | Impact Factor (2015): 6.391}

[17].[18]Reported a world background range as (7 - 221) ppm. Chromium is present as Cr3+ in most soils, usually hosted within mineral structures or with $\mathrm{Fe} 3+$ oxyhydroxides. It is slightly mobile (only in very acid media), and usually its compounds are very stable in soil. Parent rocks are the main factor controlling its concentration in soil and sediments. Chromium distribution in the studied soil samples is log - normal; well emphasized. The concentration range in the samples is $(0.5$ - 191.9) ppm. Cr concentrations in soil sample is higher than world health organization concentrations and values is about (1-5)ppm.Cr spatial distribution show higher values in the south-west parts of the lake.

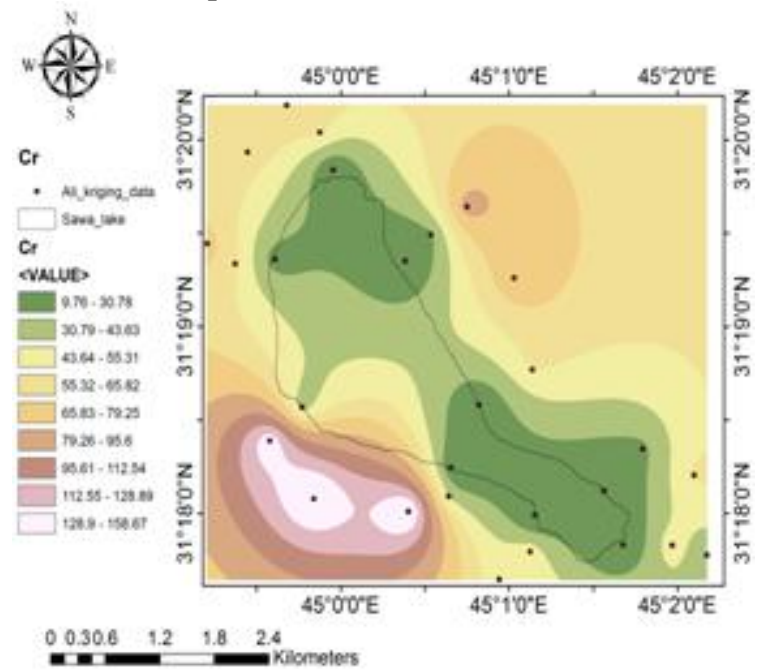

Figure 2: Distribution of $\mathrm{Cr}$ in the surface $(0-15 \mathrm{~cm})$ sediments (mg/kg).

Nickel is easily mobilized during weathering and coprecipitated with $\mathrm{Fe}-\mathrm{Mn}$ oxides or organically bound in soil [18]. Nickel content in soil is highly dependent on climate and parent rock composition. Nickel (Ni) was detected in samples of the surface layer. the identified value exceed maximum allowable concentration of world health organization concentrations and values its about (30-75) ppm ,. Nickel in the soil samples of the lake area distribution with a range of $(13.3-93.98) \mathrm{ppm}$.

Distribution and behavior of metals in aquatic environments is very complex and determined by many physical and chemical processes, such as complexation with inorganic and organic ligands, formation of colloid complexes, participation in redox and biological reactions. Hydrodynamics, biogeochemical processes and environmental conditions (redox, $\mathrm{pH}$, temperature) of the individual system [19].
Table 1: Further influence these processes. Chemical concentration of $\mathrm{Cr}$ and $\mathrm{Ni}$ in study area soils with their coordinates

\begin{tabular}{|c|c|r|r|r|r|}
\hline longitudes & latitudes & $\mathrm{Ni}$ & $\mathrm{Cr}$ & Depth & $\mathrm{S}$ \\
\hline 45.026039 & 31.302025 & 16.97 & 2.3 & $15-0$ & 1 \\
\hline 45.029865 & 31.305769 & 41.96 & 21.03 & $15-0$ & 2 \\
\hline 45.013683 & 31.309679 & 18.2 & 4.72 & $15-0$ & 3 \\
\hline 45.018959 & 31.312836 & 85.49 & 61.2 & $15-0$ & 4 \\
\hline 45.008924 & 31.324873 & 34.73 & 19.22 & $15-0$ & 5 \\
\hline 45.012508 & 31.327372 & 92.41 & 100.71 & $15-0$ & 6 \\
\hline 44.997940 & 31.333996 & 86.5 & 65.1 & $15-0$ & 7 \\
\hline 44.994639 & 31.336414 & 90.21 & 68.24 & $15-0$ & 8 \\
\hline 44.993462 & 31.322699 & 29.6 & 13.6 & $15-0$ & 9 \\
\hline 44.989532 & 31.322257 & 85.49 & 60.89 & $15-0$ & 10 \\
\hline 44.986778 & 31.324088 & 93.98 & 75.1 & $15-0$ & 11 \\
\hline 44.992980 & 31.306476 & 62 & 171.97 & $15-0$ & 12 \\
\hline 44.996154 & 31.309481 & 26.4 & 12.11 & $15-0$ & 13 \\
\hline 45.006683 & 31.300178 & 59.4 & 191.9 & $15-0$ & 14 \\
\hline 45.010655 & 31.301522 & 49.03 & 31.3 & $15-0$ & 15 \\
\hline 45.019166 & 31.299843 & 16.26 & 0.5 & $15-0$ & 16 \\
\hline 45.018746 & 31.296568 & 74.2 & 62.39 & $15-0$ & 17 \\
\hline 45.015656 & 31.294105 & 69.3 & 44.4 & $15-0$ & 18 \\
\hline 45.032784 & 31.297160 & 90.76 & 60.7 & $15-0$ & 19 \\
\hline 45.036241 & 31.296275 & 41.33 & 19.73 & $15-0$ & 20 \\
\hline 45.006359 & 31.322537 & 17.52 & 0.5 & $15-0$ & 21 \\
\hline 45.010887 & 31.304085 & 27.11 & 4.9 & $15-0$ & 22 \\
\hline 45.027940 & 31.297189 & 13.3 & 0.5 & $15-0$ & 23 \\
\hline 44.999243 & 31.330666 & 17.91 & 0.5 & $15-0$ & 24 \\
\hline 44.997320 & 31.301288 & 60.7 & 181.9 & $15-0$ & 25 \\
\hline 45.017142 & 31.321008 & 88.9 & 80.9 & $15-0$ & 26 \\
\hline 45.034964 & 31.303430 & 72.6 & 62.9 & $15-0$ & 27 \\
\hline 44.990776 & 31.332238 & 75.99 & 64.7 & $15-0$ & 28 \\
\hline & & & & & \\
\hline
\end{tabular}

Furthermore, different metals exhibit different affinities for the various solid-phase fractions of sediment [20]. This variability of factors may explain the fact that detected levels of heavy metals in Lake sawa.

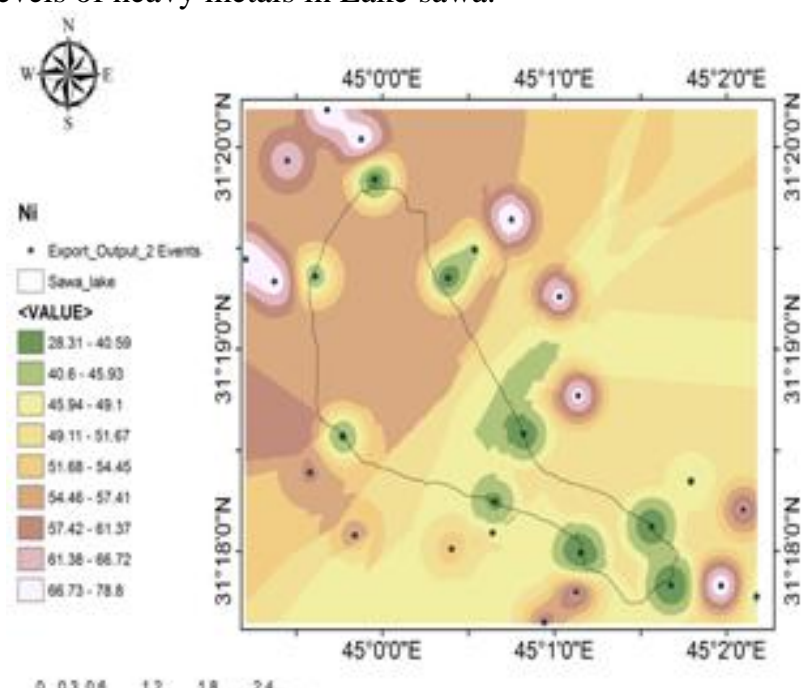

Figure 3: Distribution of Ni in the surface $(0-15 \mathrm{~cm})$ sediments (mg/kg).

\section{Conclusions}

1) Detected levels of heavy metals in sediments of Lake sawa varied within a wide range: Cr from 0.5 to 191.9 $\mathrm{mg} / \mathrm{kg}$, Ni from 13.3 to $93.98 \mathrm{mg} / \mathrm{kg}$.

2) Detected levels of most heavy metals: (Cr,Ni) exceeded maximum allowable concentrations of world health 


\section{International Journal of Science and Research (IJSR) \\ ISSN (Online): 2319-7064 \\ Index Copernicus Value (2013): 6.14 | Impact Factor (2015): 6.391}

organization 2003, thus high potential threat to the water ecosystem and even human health may be assumed.

3) A comparison of heavy metal amounts and spatial distribution patterns in the two layers of sediments reveals higher pollution levels in the surface layer of soil in the area.

\section{References}

[1] Facchinelli, A., Scchi, E., and Mallen, L. (2001). Multivariate statistical and GIS-based approach to identify heavy metal sources in soils.Environ. Pollut.114, 313-324.

[2] Shayley H., McBride M, and Harrison E. (2009). Sources and Impacts of Contaminants in Soils. Cornell Waste Management Institute.pp.1-6.

[3] Stavrianou W. (2007). The Western Australian Contaminated Sites Act 2003: The Applicability of Risk Assessment as a basis for the Assessment and Managementof Site Contamination,www.awu.edu.au pp. 1-92.

[4] JARUP L. (2003): Hazards of heavy metal contamination. Brazilian Medical Bulletin, 68: 425462.

[5] Suciu I., Cosma C., Todica M., Bolboaca S.D. and Jantschi L. (2008). Analysis of Soil Heavy Metal Pollution and Pattern in Central Transylvania. International Journal of Molecular Sciences, 9(4) : 434453.

[6] Adelekan B. A. and K. D. Abegunde (2011). Heavy Metals Contamination of Soil and Groundwater at Automobile Mechanic Villages in Ibadan, Nigeria. International Journal of the Physical Sciences vol. 6(5), pp. 1045-1058.

[7] Yahaya A., Adegbe A. A. and Emurotu J. E. (2012). Assessment of Heavy Metal content in the Surface Water of Oke-Afa Canal Isolo Lagos, Nigeria. Archives of Applied Science Research, 4(6), pp. 23222326.

[8] Ene A., Boşneagă A. and Georgescu L. (2009). Determination of Heavy Metals in Soils using XRF Technique, University of Galati, Faculty of Sciences, Chemistry Department, 111 Domneasca St, 800201 Galati, Romania pp. 815-820.

[9] Hardy D. H., Myers J. and Stokes C. (2008). Heavy Metals in North Carolina Soils Occurrence \& Significance. N.C. Department of Agriculture and Consumer Services, pp. 1-2.

[10] Asio V.B. (2009). Heavy metals in the Environment and their Health effects. Soil and Environment, pp.1-5.

[11] Wuana R. A. and Okieimen F. E. (2011). Heavy Metals in Contaminated Soils: A Review of Sources, Chemistry, Risks and Best Available Strategies for Remediation, ISRN Ecology, vol. 2011, Article ID 402647, 20 pages, doi:10.5402/2011/402647.

[12] Lenntech (2010). Heavy Metals. www.lenntech.com. Accessed on 2nd July, 2012. pp.1-3.

[13] Chen YF. 2011. Review of the research on heavy metal contamination of China's city soil and its treatmentmethod. China Population, Resources and Environment, 2011, 21(3): 536-539
[14] Hassan, W.F.,( 2007): The physio - chimical Characteristic of Sawa Lake Water in Samawa City Iraq. Marina Mesopotamica, 22:167-179.

[15] Oliver M. A., Webster R. 1990. Kriging: a methodof interpolation for geographical information system.Geographical Information Systems. Vol. 4(3):313-332.

[16] Aubert H. \& Pinta M, (1977). Trace Elements in Soils, Developments in Soil Science 7, Wlsevier Scientific Publishing company, Amesterdam, 395p.

[17] Hawkes, H.E. and Webb, J.S., 1962. Geochemistry in Mineral Exploration. Harper and Row Co., 377pp.Iraq Meteorological Organization, 2000. Climatic Map of Iraq. Ministry of Transportation.

[18] Kapata - Pendias, A. and Pendias, H., 2001. Trace elements in soils and Plants. 3rd edit., CRC Press LLC, USA, 388pp.

[19] Canavan R. W., Van Cappellen P., Zwolsman J. J. G.,van den Berg G. A., Slomp C. P. 2007. Geochemistryof trace metals in a fresh water sediment: field resultsand diagenetic modelling. Science of TotalEnvironment. Vol. 381: 263-279.

[20] Calmano W., Hong J., Forstner U. 1993. Bindingand mobilisation of heavy metals in contaminatedsediments affected by $\mathrm{pH}$ and redox potential.Water Science and Technology. Vol. 28(8-9): 223-235.

\section{Author Profile}

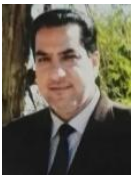

Dr. Ayad Kadhim Ali is graduated from university of Baghdad and got his $\mathrm{phD}$ in soil survey and classification, now an Assistant Professor doctor and serve as associate dean of the faculty of agriculture in university of Kufa .Iraq.

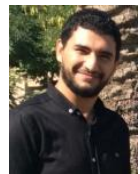

Ali Khalil al-khafajy graduated from University of Al-Muthanna. Iraq ,In addition, currently undergraduate student in same University at agriculture. 